\title{
El conflicto armado como factor de transformación territorial del Oriente de Caldas, Colombia ${ }^{1}$
}

\author{
The armed conflict as a factor of territorial transformation of the West of Caldas, \\ Colombia
}

Recibido: 03 de marzo de 2017 - Revisado: 29 de septiembre de 2017 - Aceptado: 06 de febrero de 2018.

Diego A. Narváez Medina²

\section{Resumen}

El objetivo del presente artículo es comprender las transformaciones territoriales del Oriente de Caldas por efectos del conflicto social. La metodología utilizada tiene un carácter procesual, integrada por la descripción, la explicación y la interpretación, mediante la cual se busca la comprensión de los principios ocultos de las realidades que se interpretan. Se encontró que el conflicto armado afectó las relaciones de vecindad y de solidaridad, deprimió los espacios productivos debido al abandono de miles de campesinos de sus tierras. En conclusión, el conflicto social es un elemento inherente a toda relación social e indispensable para imprimirle movimiento a la sociedad; no obstante, la forma de resolución adoptada, conduce a cada sociedad por el camino de la democracia o la enfrasca en una espiral de violencia fratricida.

\section{Palabras clave}

Dinámicas territoriales, conflicto, región, poder, ecogénesis, Caldas.

\begin{abstract}
The objective of this article is to understand the territorial transformations in eastern Caldas (Colombia) due to the effects of social conflict. Through a process-based methodology, the aim was to understand the hidden principles of the interpreted realities, by integrating description, explanation and interpretation. It was found that the armed conflict affected neighborly and solidarity relations and, because thousands of peasants abandoned their lands, the productive spaces was desolated. In conclusion, social conflict is an inherent element of any social relationship but is essential to imprint movement on society; nevertheless, the selected way to resolve a conflict, leads each society on the path of democracy or engages it in a spiral of fratricidal violence.
\end{abstract}

\section{Keywords}

Territorial dynamics, conflict, region, power, ecogenesis, Caldas.

\footnotetext{
${ }^{1}$ Este artículo hace parte del proceso de investigación de la Tesis Doctoral titulada: Las dinámicas territoriales del oriente de Caldas, Colombia: la territorialización del poder y el poder de la territorialización. Desarrollada en el Doctorado de Estudios Territoriales del ICSH-Universidad de Caldas, bajo la dirección de la Dra. Beatriz Nates-Cruz, y financiado por la Vicerrectoría de Postgrados e investigaciones de la Universidad de Caldas.

2 Profesor Asociado del Departamento de Desarrollo Humano de la Universidad de Caldas, Caldas, Colombia. Candidato a Doctor en Estudios Territoriales. Miembro ICSHUNICALDAS, Grupo de Investigación Territorialidades y RETEC.

Correo electrónico:

narvaezmedina@gmail.com (10) https://orcid.org/0000-0002-26534380

Para citar este artículo use: Narváez, D. (2018). El conflicto armado como factor de transformación territorial del Oriente de Caldas, Colombia. Civilizar, 18(35), 13-23. doi:10.22518/usergioa/jour/ $\operatorname{ccsh} / 2018.2 / \mathrm{a} 02$
} 


\section{Introducción}

El presente artículo tiene como objetivo comprender las dinámicas territoriales a partir de un fenómeno fuertemente sociológico como lo es el conflicto social. En otras palabras y parafraseando a Santos (2000, p. 20), las categorías de análisis utilizadas para construir o poner en evidencia el problema territorial deben unirse al contenido existencial, es decir, deben reflejar la propia ontología del espacio. Para ello se abordan dos realidades sociales que son la base de las transformaciones territoriales en el Oriente de Caldas: 1) El poder: definido como producto de las relaciones sociales, lo cual reafirma el carácter fluido del poder, es decir, que las relaciones de poder no se pueden entender como la oposición binaria entre dominadores y dominados (Foucault, 1986). Tomo el poder como la expresión de la territorialización en las relaciones de fuerza y apropiación del espacio, esto es, la dimensión espacial de las relaciones de poder. 2) El orden territorial, entendido como interdependencia entre elementos que se condicionan mutuamente y cuyas interacciones hacen aparecer nuevas relaciones con sus propios ritmos de cambio (Tinland, en Santos, 2000, p. 29). El orden se toma aquí como el proceso ecogenético de configuración y reconfiguración territorial que se ha producido durante los últimos 35 años en la zona de estudio.

Para abordar el problema de estudio, se planteó una metodología de carácter procesual, inspirada en Bourdieu, Chamboredon y Passeron (2002), que plantea tres etapas: 1) la descripción, dirigida a indagar sobre las características constitutivas del fenómeno u objeto, 2) la explicación, etapa en la cual se recurre a los elementos teóricos y conceptuales elegidos en relación con el objeto de estudio construido, y 3) la interpretación, momento de la investigación en el que se alcanza el mayor nivel de abstracción, mediante el cual se busca la comprensión de los principios ocultos de las realidades que se interpretan, o parafraseando a los mismos autores, se pretende establecer y visibilizar la relación de las relaciones ocultas en el objeto de investigación seleccionado (p. 78). Debido al carácter cualitativo de la investigación se adoptó el trabajo de campo como la herramienta fundamental para acopiar la información y contrastar los presupuestos teóricos.

\section{El poder de la territorialización y la desterritorialización}

Como presupuesto para abordar el poder de la territorialización, partimos de asumir el territorio, la territorialización y la territorialidad como un círculo dialéctico, en el que la territorialización como acto produce nuevos territorios; a su vez, el concepto de territorio, se asume como el espacio apropiado, transformado y valorizado por y en las relaciones sociales (Raffestin, 2011); por la tanto, trae implícita la idea de dominio y gestión dentro de un espacio determinado (Andrade, 2002).

En términos de Monnet (1999), el espacio es territorializado por un actor geográfico, o por un actor sintagmático ${ }^{1}$ de acuerdo a Raffestin (2011), que actúan en, sobre y con el espacio; vale la pena aclarar que el actor puede ser individual o colectivo, lo cual implica que el territorio en tanto producto, es producido (Lefebvre, 2013) "en ciertas condiciones, para ciertos fines, por ciertos actores, con los cuales un grupo se apropia, delimita y transforma el espacio" (Monnet, 1999, p. 2); de otra parte Escobar (2010) llama la atención sobre la importancia de realizar un "examen de los procesos basados-en-lugar y regionales desde perspectivas multiniveles económicos, ecológicos y culturales, [de lo cual se derivan] nuevas oportunidades para la comprensión de las políticas de la diferencia y mismidad que acompañan en acciones de la globalidad" (p. 21), generando un espacio ideado, expresión de los valores que los seres humanos atribuyen a un espacio físico o a un uso del espacio que se condensa en la territorialidad. 
En la sociedad moderna, los individuos y los grupos siempre han dividido el espacio, marcado límites y establecido fronteras, ejercicio de territorialización mediante los cuales se producen territorios, pero, a su vez se desterritorializa, en tanto las líneas divisorias materiales e imaginarias generan ipso facto un "nosotros" y un "ellos" (Sack, 1986), o sea que producen exclusión. Así, la tendencia a acotar, cercar y delimitar el espacio, está aparejada a la necesidad de diferenciarse. Uno de los productos de la territorialización, es la región, una formación socioespacial siempre cuestionada y centro del debate entre la concepción que reconoce el espacio como un objeto instrumental de planificación territorial, y la que concibe el espacio imaginado cómo ámbito de la mediación social (Raffestin, 2011; Di Méo, 1998).

El acto de separar mediante el establecimiento de fronteras o límites físicos como los oprobiosos muros que se creyó superados al derribar el muro de Berlín, han resurgido con mayor fuerza para detener la movilidad por el mundo de seres humanos desplazados por la pobreza y las guerras internas. En este sentido, las nociones de "territorialidad general" y "territorialidad restringida" planteada por Raffestin (2011), tiene una gran cercanía conceptual con la formulada por García (1979) de "exclusividad positiva" y "exclusividad negativa".

Tanto la una como la otra, son expresión de la acción territorializante de un individuo, grupo o sociedad determinados. Así, la "territorialidad restringida", se presenta mediante la exclusión espacial de un grupo por otro y dan origen -en términos de Raffestin- "a las asimetrías más dramáticas, a los poderes más encarnizados y más retrógrados" (2011, p. 7). Los dos autores coinciden en que tal situación de exclusión y asimetría es capaz de sacar a relucir los instintos animales de los humanos; más aún, si la norma, racionalmente concertada, se ha desdeñado como medio de resolución de los conflictos sociales.
Los dos anteriores, son conceptos relacionados que permiten entender los altos grados de pugnacidad y barbarie a los que han llegado los conflictos $^{2}$ como el colombiano, el sirio, el afgano, entre otros; niveles que no se podrían concebir si la realidad no mostrara cómo la sevicia puede ser dirigida, incluso, contra personas que hasta hace poco tiempo hacían parte de la proximidad espacial y afectiva del agresor. Foucault, nos advierte respecto a la ilusión que hemos depositado en la racionalidad como instrumento para abolir la violencia; frente a lo cual señala el autor, categóricamente: "Es completamente falso. Entre violencia y racionalidad no hay incompatibilidad. Mi problema no es condenar la razón, sino determinar la naturaleza de esta racionalidad que es compatible con la violencia" (Foucault, 2012, p. 20).

\section{La relación Estado-Región en "la trampa territorial"}

La noción de región hace parte de una dimensión mayor conocida como Estado-Nación. El tratado de paz de Westfalia de 1648 dio lugar al inicio de un nuevo orden basado en el concepto de soberanía nacional y el principio de integridad territorial como fundamento de la existencia de los Estados-Nacionales. El Estado como forma de organización social predominante durante la modernidad, ha conducido a caer en lo que Agnew denomina "la "trampa territorial", que se expresa en "el pensar y actuar como si el mundo estuviese enteramente constituido por Estados que ejercen su poder sobre bloques de espacio y de este modo se constituyen en el único referente geográfico-político de la política mundial" (2005, p. 60).

Ahora en cambio, los pobladores constituyen una comunidad ${ }^{3}$ base de la construcción de la nación y asociada a un Estado. Dicho en términos de Fraser (2008) "el imaginario político westfaliano investía al Estado de una soberanía indivisa y exclusiva sobre su territorio, que impedía la "interferencia externa" en sus "asuntos internos" (p. 12). Siguiendo a Fraser, 
esta nueva visión del mundo estableció una clara división del espacio político, en tanto que “el espacio 'interno' se concebía como el ámbito civil y reino del contrato social, sometido a la ley y a las obligaciones de la justicia, y el espacio 'internacional' se contemplaba como un espacio en discusión de regateo estratégico" (p. 12).

La historia de la guerra interna en Colombia nos muestra cómo, aún en 2018, el "espacio interno" sigue en disputa, buena parte del territorio Colombiano esta militarizado, y en él, no opera el contrato social, sino la coerción del grupo armado que hace presencia en ese lugar. En contrapartida, la región como expresión territorial que se acerca a la lugarización, la cual busca la identidad personal y local y privilegia lo autóctono, lo vernáculo, lo natural y lo singular (Escobar, 2000). Dicho en términos de Milton Santos (2000):

El orden local es asociado a una población contigua de objetos, reunidos por el territorio y como territorio, regidos por la interacción [...]. El orden local funda la escala de lo cotidiano y sus parámetros son la co-presencia, la vecindad, la intimidad, la emoción, la cooperación y la socialización con base en la contigüidad (pp. 289-290).

\section{La región un territorio imaginado más no delimitado}

Actualmente el concepto de región es una de la nociones más inasibles de los estudios territoriales (Raffestin, 2011; Giménez, 2000); no obstante, hay que recordar que a finales del siglo XIX, esta formación socioespacial tuvo un gran protagonismo, llegando a constituirse en el espacio síntesis de las dimensiones natural y humana, e incluso, para algunos geógrafos como Hettner y Vidal de la Blanche -representantes de la tendencia corológica ${ }^{4}$ - la región debía ser el objeto de estudio de la geografía (en Hiernaux y Lindon, 1993, p. 90). Además de la geografía, la economía regional y del desarrollo, se interesaron por el desarrollo desigual de las regiones; pero esos trabajos trataban a las regiones como un corolario de los procesos económicos y políticos y "no como una unidad fundamental de la vida social" (Storper, 1997, citado en Soja, 2008, p. 257).

El concepto de región tiene un carácter extremadamente elusivo nos dice Giménez y retoma una diciente frase de Van Young para enfatizarlo: "Las regiones son como el amor, son difíciles de describir, pero cuando las vemos las sabemos reconocer" (en Giménez, 2000, p. 110) y retomamos la definición formal propuesta por Van Young, quien dice que, como todo territorio "la región no constituye un dato a priori, sino un constructo fundado sobre criterios geográficos, económicos, político-administrativos, histórico-culturales", por lo tanto, concluye diciendo que "las regiones son más bien hipótesis que necesitan ser probadas antes que datos que deben ser registrados " (citado en Giménez, 2000, p. 111).

Una región es un producto geosociohistórico, se expande o recoge de acuerdo con las dinámicas sociales que ocurren en su interior, está constituida de elementos físicos y humanos que le dan unidad y la distinguen de otras formaciones socioespaciales; no obstante, más que la homogeneidad o heterogeneidad, es la integración de la diversidad de elementos lo que determina la existencia de una región (Fals Borda, 1996).

La región, se muestra en el plano formal, como una unidad, pero en términos vivenciales los ritmos la dinamizan al compás de las transformaciones de la vida cotidiana. Su radio de acción espacio-temporal no afecta la dinámica de la vida familiar o el círculo social, y no alcanza a perturbar los hábitos; al igual que en la práctica, contribuye a conformar la vida profesional. De acuerdo a Di Méo (1998), "la idea de región coincide con la idea de un espacio intermedio" (p. 131), así que el ámbito cotidiano de la región está delimitado por la distancia requerida para realizar viajes frecuentes. "Ellos no nos conducen jamás muy lejos de nuestra casa, 
tiende frecuentemente a multiplicar los chez nous (Di Méo, 1998, p. 132).

\section{La ecogénesis del oriente de Caldas}

La analogía ha sido un recurso metodológico de la Ciencias Sociales para facilitar la compresión de la compleja realidad social, tomando como referencia un objeto de naturaleza diferente, pero más cercano a nosotros; famosa es la analogía parsoniana ${ }^{5}$, de origen biológico entre el organismo humano y el "organismo social". La relación del cuerpo humano y el cuerpo de la tierra que nos presenta Raffestin, tienen el interés -según el mismo autor- de hacer comprender que las nociones de espacio y territorio difieren en su contenido. El cuerpo humano -nos dice el autor- comprende un conjunto de órganos que se pueden calificar de endosomáticos: son los instrumentos fenotípicos. Pero en el proceso civilizatorio el ser humano ha producido una innumerable cantidad de instrumentos exosomáticos, que él ha creado y crea a partir de instrumentos endosomáticos y de los instrumentos exosomáticos que ya posee (Raffestin, 1986, p. 176). Continuando con el planteamiento del autor:

El cuerpo de la tierra es también constituido por instrumentos endosomáticos: la tierra, el mar, las montañas y los ríos, los bosques y los desiertos, etc. En efecto, todas las morfologías que no le deben nada a la acción antrópica. El territorio es un macro-instrumento exosomático que resulta de la capacidad que tienen los hombres de transformar mediante su trabajo, tanto la naturaleza que le rodea como sus propias relaciones sociales. El territorio es el producto de la transformación de la endosomática terrestre por la exosomática humana. La ecogénesis territorial es la crónica de un "cuerpo a cuerpo", la historia de una relación en la cual la naturaleza y la cultura se fusionan. (Raffestin, 1986, p. 177)

En la historia del "cuerpo a cuerpo", que libran la naturaleza y la cultura para configurar una ecogénesis particular (Raffestin, 1986), el Oriente de Caldas ${ }^{6}$ se formó por la integra- ción endosomática del valle y la montaña, y los efectos exosomáticos del conflicto armado, a la vez destructivo e integrador. Los procesos de producción social del espacio y de las configuraciones territoriales se caracterizan por estar aparejados con el surgimiento de conflictos sociales. De manera general se puede decir, que no existe un orden espacial que no sea fruto del conflicto o dinamizado por este (Haesbaert, 2011; Peña, 2008). Aquí se ponen en juego las distintas territorialidades que se construyen sobre un mismo territorio, y que llevan a que los distintos actores geográficos creen estrategias para hegemonizar la suya en un espacio y tiempo delimitados. Soja (2014), afirma que no es posible hablar de espacialidad sin tener en cuenta la perspectiva del conflicto, pues este atraviesa la dinámica social. A continuación se presenta un bosquejo de lo que ha sido el conflicto armado en la región de referencia, en la que se observa la gran capacidad de transformación territorial de este fenómeno social.

En el intento de comprender la racionalidad del conflicto armado colombiano, Franco, nos muestra que hay una serie de elementos subjetivos que mueven a los actores de un conflicto, y que no se pueden reducir a motivaciones restrictivas como la seguridad y el odio o enmarcar el sentido de su accionar en la dualidad entre agravio-codicia, la autora nos dice que "este tipo de conflicto, no es entonces, nada diferente a la interacción entre distintos actores, motivaciones e intereses bajo un contexto histórico y espacial determinado" (2009, p. 87). La autora retoma uno de los planteamientos de Kalyvas, quien señala que "la ambigüedad ampliamente observada es fundamental más que incidental a las guerras civiles; un asunto de estructura más que de ruido" (Citado por Franco, 2009, p. 87).

Frente a la ambigüedad presente en el conflicto, se puede decir que en el Oriente Caldense hubo tres momentos en su devenir. El primero, que se ubica entre finales de la década del setenta y el primer lustro del ochenta, que tiene 
como escenario el valle del Magdalena, cuando se generaron los procesos de organización de las Autodefensas Campesinas que luego darían origen a la Asociación de Comerciantes, Ganaderos y Agricultores del Magdalena Medio, ACDEGAM, con la personería jurídica otorgada por la Gobernación de Boyacá, organización utilizada como fachada para traficar con armas y realizar los pagos a los contingentes paramilitares del Magdalena Medio (Durán, 2013, pp. 12-15). Surgieron con el propósito de poner fin a las extorsiones y los secuestros que realizaba el grupo ilegal, autodenominado Fuerzas Armadas Revolucionarias de Colombia, FARC, contra los propietarios de la zona. En una segunda etapa, su objetivo inicial - de autodefensa- tuvo un giro a partir de 1985, expulsada la guerrilla, su modus operandi adquirió la execrable connotación de "limpieza social"7, sus nuevos objetivos militares fueron las personas diferentes ${ }^{8}$ e incómodas.

Con la complicidad de los altos mandos militares del batallón Bárbula, el apoyo de muchos de los grandes ganaderos de la zona y las alianzas que hicieron con los narcotraficantes del "cartel de Medellín", se convirtieron en un ejército narco-paramilitar, lo que les facilitó imponer un orden socioespacial de facto en el Magdalena Medio; para lo cual, La Dorada jugó un papel geoestratégico importante porque es la "puerta de entrada" al Oriente Montañoso. En esta etapa de la guerra, las fuerzas paramilitares, en connivencia con las del Estado, son las responsables del aniquilamiento sistemático de sindicalistas, defensores de Derechos Humanos y de miles de militantes del partido Unión Patriótica9.

La tercera etapa del conflicto armado inició en 1999, cuando las FARC, aprovechando la distensión armada que se produjo durante los diálogos de paz del Caguán (1999-2001), convirtieron el Oriente de Caldas en un territorio de refugio y tránsito para trasladar sus enfermos y secuestrados. Con tal propósito, los frentes $9^{\circ}$ y $47^{\circ}$, procedentes del sur de Antioquia, incursionaron en los corregimientos de Florencia, San Diego, Berlín y Encimadas, del municipio de Samaná, y en el corregimiento de Arboleda, del municipio de Pensilvania (ver Apéndice: Mapa del Oriente Caldense), con la clara intención de tomar control del territorio; y los paramilitares que ya se habían fortalecido en el valle, subieron a la montaña, inicialmente al municipio de Norcasia, en donde contaron con la colaboración de la fuerza pública y la administración municipal, con lo cual se iniciaron los hostigamientos y combates continuos con la guerrilla en la zona de montaña, por el dominio territorial. El objetivo principal de los paramilitares era contener a las FARC y proteger el proceso de construcción del embalse del Proyecto Hidroeléctrico Miel I, el cual, era de alto interés de la guerrilla por su importancia geográfica y económica.

\section{EI conflicto armado como factor de transformación territorial}

El conflicto armado fue atizado por los recursos derivados de la siembra de la coca, actividad a la que se dedicaron la mayoría de los campesinos agobiados por la crisis cafetera ${ }^{10} ; \mathrm{y}$ la producción cocalera se vio "favorecida" por la protección de los miembros de la policía y el ejército nacionales instalados en la región. Todos los actores armados se lucraron de los cultivos ilícitos, y la gran afluencia de dinero exacerbó el conflicto armado, cambió la economía regional, trastocó el sentido del trabajo honrado y digno por el dinero fácil y el afán de consumo; en fin, se trastocó el orden local establecido, alteró la vida cotidiana, las relaciones de vecindad fueron impregnadas de pugnacidad y cargadas de estigmatización territorial entre los pobladores del valle y los de la montaña, como lo ilustra muy bien el siguiente testimonio:

[...] porque era así: Encimadas, todo lo que era Santa Rita, El Silencio, unas veredas, era guerrilla. Esa era la parte alta de Samaná. La parte baja, que es un clima cálido, es Sasaima, Confines, Cañaveral, todo lo que es zona de 
influencia del embalse de La Miel, era zona paramilitar. Entonces en realidad, había gente que no podía echar ni pa' arriba, ni pa' abajo, porque a veces estaban tildados por ser amigo o familiar de algún miliciano o paramilitar, entonces no echaban para allá. [...] Yo saqué mi cédula en Bogotá, porque uno decir que era de Samaná en La Dorada o Cañaveral, era miedoso, porque lo tachaban de guerrillero." (L. Palacios, comunicación personal, 21 de mayo de 2015).

Uno de los grandes impactos del conflicto armado fue el desplazamiento forzado, asumido por Escobar como la ausencia de lugar - una "condición generalizada de desarraigo"-, se ha convertido en el factor esencial de la condición moderna, una condición muy aguda y dolorosa en muchos casos, como en el de los exiliados y refugiados (2000, p. 113). En efecto, el desplazamiento forzado es un proceso de desterritorialización, de destierro y exilio, que obligó a los pobladores a abandonar intempestivamente sus espacios de vida, por la presión que ejercieron los grupos armados ilegales, con todo lo que esta decisión implica a futuro. Según Arraou (1999), el desplazado es un individuo que se debate entre dos territorios, entre dos memorias sociales. Su identidad se inscribe en los marcos sociales, que varían en el espacio, el aquí y el allá; el tiempo de antes y el de ahora; y la lengua, la de origen y la de adopción (Citado en Palacio et al., 2003, p. 46).

El sujeto desplazado sufre la desterritorialización, puesto que ha sido desarraigado forzadamente de su territorio y llega a un espacio ajeno y se enfrenta a nuevas e inesperadas situaciones sociales, emocionales y económicas. $\mathrm{La}$ construcción de una nueva territorialidad está limitada y depende de la "ayuda" de amigos y familiares y de las entidades gubernamentales; mientras tanto debe soportar la incertidumbre del mañana y la provisionalidad de los "espacios prestados", que afectan su dignidad. Esta situación obliga a los sujetos a transitar por distintos espacios en diferentes escalas territoria- les (local, regional, nacional, internacional), en busca de una nueva oportunidad; casi siempre provienen de las zonas rurales y se asientan en las urbanas, y habitualmente, su única opción de subsistencia es el llamado "rebusque". Son los sujetos desplazados, población incómoda para el régimen, porque su sola existencia pone en cuestión la moral de toda la sociedad.

Otro de los efectos del conflicto armado fue la afectación de los espacios productivos. Con la llegada de los grupos armados, el espacio productivo se deprimió debido al abandono de miles de campesinos de sus tierras y la mayoría de los grandes comerciantes dejaron sus negocios, quienes se encargaban de proveer los insumos para las labores agropecuarias. Unos fueron secuestrados, otros "boleteados"11 y todos extorsionados. Las dos razones anteriores condujeron, de una parte, al aumento en la concentración de la tierra, debido a que muchos terratenientes aprovecharon la situación para adquirir tierras a muy bajos costos, convirtiéndose en una de las grandes transformaciones territoriales generadas por el conflicto armado, especialmente en La Dorada y Samaná, como lo demuestra el índice de Gini que fluctúa entre 0,819 y 0,958 (Instituto Geográfico Agustín Codazzi-IGAC, 2012, p. 204), el rango más alto de concentración de la propiedad de la tierra en el país; y de la otra, el cambio en el uso de la tierra de miles de hectáreas que eran destinadas a cultivos de café y de "pan coger", por potreros para la ganadería.

\section{Conclusiones}

De lo anterior se puede concluir que en el proceso de producción de una región, interactúan diversidad de actores sociales y sus diferentes intereses se hacen evidentes en la ocupación y apropiación material del espacio, como en su valoración simbólica, revestida del doble carácter: conflictivo y dinámico. El conflicto como un elemento inherente a toda relación social es un hecho históricamente observable e indispensable para imprimirle movimiento a la sociedad; no obstante, la forma en que lo re- 
suelve cada sociedad, en un momento determinado, ya sea por la vía democrática en donde predomina el consenso en la lucha por el poder; o al contrario, por la vía autoritaria en donde predominan el despotismo y el poder es ejercido por la coacción, da lugar a la creación de órdenes socioespaciales de facto, en donde el conflicto armado seguirá nutriéndose de intereses sectarios, odios y debilidad institucional del Estado.

El oriente de Caldas es una región históricamente ensamblada, aunque presenta una tensión constante; de una parte, sus diferencias morfológicas, económicas y socioculturales que tienden a fragmentar la montaña del valle, y de la otra, las relaciones de vecindad, sus dinámicas poblacionales e intercambios económicos y poderes políticos locales y regionales, tienden a integrarla. Parafraseando a Massey (2012), esta región tiene que ser conceptualizada, no como una simple diversidad, sino como una región de encuentro y de trayectorias potencialmente conflictivas, la cual encaja dentro de, y está internamente constituida por, geometrías complejas de poder diferenciado.

Si bien la región ha adquirido protagonismo en las últimas tres décadas como correa de transmisión entre lo local y lo global, no podemos desdeñar el hecho de que la noción de región no designa ninguna realidad objetiva, no remite a ningún soporte espacial delimitado, como lo hemos podido constatar en el intento, fallido hasta ahora, de la Constitución Política de 1991, de abrir las posibilidades de crear regiones (Art. 306); así que, la región puede convertirse, a la larga, más en un objeto de carácter discursivo, que una construcción social derivada de prácticas sociales que la objetiven como formación socioespacial con sentido para sus pobladores.

\section{Referencias}

Agnew, J. (2005). Geopolítica: una re-visión de la política mundial. Trama editorial.

Andrade, M. C. de. (2002). Territorialidades, desterritorialidades, novas territorialidades: Os limites do poder nacional e do poder local. En M. Santos, M. A. Souza, y M. L. Silveira, Território: Globalização e fragmentação, 5a. Ed., (p.p. 213-220). São Paulo: Hucitec / Anpur.

Bourdieu, P., Chamboredon, J. C., y Passeron, J. C. (2002). El oficio de sociólogo. Presupuestos epistemológicos. Buenos Aires: Siglo XXI.

Coser, L. (1970). Nuevos aportes a la teoría del conflicto social. Buenos Aires: Amorrortu editores.

Di Méo, G. (1998). Géographie sociale et territoires. Paris: Editions Nathan.

Durán, D. (2013, 27 de julio). Así fue la génesis del paramilitarismo. El Espectador, pp. 12-15. Recuperado de:

https://www.elespectador.com/ noticias/judicial/asi-fue-genesis-delparamilitarismo-articulo-436386

Escobar, A. (2000). El lugar de la naturaleza y la naturaleza del lugar: ¿globalización o postdesarrollo?. En Edgardo Lander (Comp.). La colonialidad del saber: eurocentrismo y ciencias sociales. Perspectivas Latinoamericanas. Buenos Aires: CLACSO, Consejo Latinoamericano de Ciencias Sociales. Recuperado de: http://biblioteca.clacso.edu.ar/clacso/sursur/20100708045100/7_escobar.pdf

Escobar, A. (2010). Territorios de diferencia: Lugar, movimientos, vida, redes. Popayán: Envión Editores.

Fals Borda, O. (1996). Región e Historia: Elementos sobre ordenamiento y equilibrio regional en Colombia. Bogotá: IEPRI, Universidad Nacional de Colombia, Tercer Mundo Editores. 
Foucault, M. (2012). El poder, una bestia magnífica. Sobre el poder, la prisión y la vida. Buenos Aires: Siglo XXI Editores.

Foucault, M. (1986). Historia de la sexualidad. 1-La voluntad del saber. México: Siglo XXI.

Franco, V. L. (2009). Orden contrainsurgente $y$ dominación. Bogotá: Siglo del Hombre Editores, Instituto Popular de Capacitación.

Fraser, N. (2008). Las escalas de la justicia. Barcelona: Herder Editores.

García, J. L. (1976). Antropología del territorio. Madrid: Ediciones Josefina Betancor.

Giménez, G. (1999). Territorio, cultura e identidades. La región socio-cultural. Estudios sobre las culturas contemporáneas, 5(9), $25-57$.

Haesbaert, R. (2011). El mito de la desterritorialización: del "fin de los territorios" a la multiterritorialidad. México, D.F.: Siglo XXI.

Hiernaux, D., y Lindon, A. (1993). El concepto de espacio y el análisis regional. Secuencia. (25), 89-110.

Instituto Geográfico Agustín Codazzi-[IGAC]. (2012). Atlas sobre la Distribución de la Tierra en Colombia. Bogotá: Universidad de los Andes.

Lefebvre, H. (2013). La producción del espacio, $3^{\text {a }}$ Ed. Madrid: Capitán Swing.

Luhmann, N. (1995). Poder. México: Editorial Anthropos.

Massey, D. (2012). Espacio, lugar y política en la coyuntura actual, Urban NSO4, 7-12.

Misión de Observación Electoral-[MOE] y Corporación Arco Iris (s.f.). Monografia político electoral del Departamento de Caldas 1997-2007. Recuperado de: http://moe.org.co/home/doc/moe_mre/ CD/PDF/caldas.pdf
Monnet, J. (1999). Globalización y territorializaciones "areolar" y "reticular": los casos de Los Ángeles y la Ciudad de México. Memorias del $V$ Seminario Internacional de la Red Iberoamericana de Investigadores sobre Globalización y Territorio. Toluca, México. Universidad Autónoma del Estado de México, pp. 2-11.

Palacio, J., Correa, A., Díaz, M., y Jiménez, S. (2003). La búsqueda de la identidad social: un punto de partida para comprender las dinámicas del desplazamiento - restablecimiento forzado en Colombia. Investigación y Desarrollo, 11(1), 26-55.

Peña, L. B. (2008). Reflexiones sobre las concepciones de conflicto en la geografía humana. Cuadernos de Geografia, Revista Colombiana de Geografia, 17, 89-115. doi:10.15446/rcdg.n17.10921

Raffestin, C. (1986). Écogénèse territoriale et territorialité. En F. Auriac. y F. Brunet (Eds.), Espaces, jeux et enjeux, (pp. 175185). Paris: Fondation Diderot, Fayard.

Raffestin, C. (2011). Por una geografia del poder. México: El Colegio de Michoacan.

Sack, R. (1986). Human Territoriality: its Theory and History. Cambridge: Cambridge University Press

Santos, M. (2000). La Naturaleza del Espacio. Barcelona: Ariel.

Simmel, G. (2010). El Conflicto, sociología del antagonismo. Madrid: Ediciones Sequitur.

Soja, E.W. (2008). Postmetrópolis, estudios críticos sobre las ciudades y las regiones. Madrid: Traficantes de sueños.

Soja, E.W. (2014). En busca de la justicia espacial. Valencia: Tirant Humanidades. 


\section{Notas}

1 Para Raffestin existen dos tipos de actores en relación con el espacio, los actores sintagmáticos son los que tienen la capacidad de transformar el espacio, a diferencia de los paradigmáticos que están en el espacio, no obstante, estos mediante su acción transformadora y en ciertas circunstancias pueden convertirse en sintagmáticos. Idea desarrollada de Greimas, A. J., en Sémiotique et sciences sociales (pp. 96-98). (Cfr. Raffestin, 2011, pp. 33-58)

2 Tanto Simmel (2010), como Luhmann (1995) y Coser (1970), asumen el conflicto social como el elemento dinamizador del cambio social y por lo tanto factor inherente a las relaciones sociales. El problema no es la presencia del conflicto en la interacción social, sino la forma como los seres humanos lo resolvemos.

3 Comunidad imaginada en el sentido de B. Anderson, (1993)

4 La tendencia corológica recorre el pensamiento geográfico desde el siglo XIX y se ha caracterizado por estudiar la diferenciación de los lugares en la superficie. El concepto de espacio y el análisis regional. Cfr. Hiernaux, D. y Lindon, A. (1993). Revista Secuencia. México: Instituto Mora/COLMEX, p. 90

5 Talcott Parsons, creador de la teoría sociológica conocida como estructural-funcionalismo, fuente conceptual de lo que sería la teoría de sistemas, la desarrolla a partir de la analogía entre los sistemas (sanguíneo, nervioso, linfático, etc.) que hacen parte del organismo humano y el cuerpo de la sociedad. Hay que recordar, que el autor antes de estudiar filosofía y sociología era biólogo. Cfr. Parsons, T. (1974). El sistema de las sociedades modernas. México, D.F.: Editorial Trillas.
6 El Departamento de Caldas se encuentra en el centro occidente de Colombia, y el Oriente de Caldas se ubica en la vertiente oriental de la cordillera central, su geografía se extiende desde la divisoria de aguas a los 3.200 m.s.n.m., hasta los 176 m.s.n.m., a orillas del río Magdalena. Su geografía vertical le proporciona los tres pisos térmicos, en donde se puede producir una gran variedad de productos agrícolas, pecuarios y forestales; la energía del relieve y la presencia de varias cuencas hidrográficas y reservas naturales como la Selva de Florencia y la Laguna de San Diego, la hacen biodiversa y de una gran riqueza hídrica; ésta última convertida a partir del 2002 en energía eléctrica mediante la construcción de la represa hidroeléctrica "La Miel".

7 Lo paradójico es que en entrevistas realizadas en La Dorada, entre los años 2013 y 2015, muchos habitantes echaban de menos esta oprobiosa práctica, así como la autoridad que manejaba el comandante paramilitar de turno que resolvía, incluso, problemas matrimoniales, mediante autoridad "compartida" con los mandatarios y políticos locales. A continuación se relacionan los casos de políticos de La Dorada investigados o condenados por nexos con grupos paramilitares: Nicolás Gómez, alcalde electo de La Dorada, 1994: condenado. Jaime Gutiérrez Ángel, alcalde de La Dorada, en 2003, por el Nuevo Partido: investigadorecluido. César Arturo Alzate, ex alcalde de La Dorada, promotor del Movimiento del Pueblo y líder del Nuevo Partido en La Dorada: investigado-recluido. Justo Capera, alcalde de La Dorada, 2007, Partido Liberal: investigado-recluido. Maribel Galvis, integrante del bloque Magdalena medio, concejal electa en La Dorada, 2000, por Actitud Renovadora: desmovilizada, prófuga (MOE, pp. 96-103). 
8 La personas y los comportamientos catalogados como diferentes eran fuertemente reprimidos y asesinadas las personas, como la población LGTBI, las prostitutas, los drogadictos, los jóvenes que tenían el pelo largo, los sindicalistas y los líderes sociales locales.

9 El exterminio sistemático perpetrado por grupos paramilitares, por narcotraficantes y por fuerzas del Estado incluyó: dos candidatos presidenciales - los abogados Jaime Pardo Leal y Bernardo Jaramillo Ossa, 8 congresistas, 13 diputados, 70 concejales, 11 alcaldes, y se calcula en cinco mil los militantes asesinados; sin contar los cientos de exiliados (Grupo de Memoria Histórica, GMH, 2013).

10 Entre 1998 y 1999, las exportaciones del grano cayeron un $30 \%$, y un $19 \%$ adicional entre el 2000 y el 2004. La crisis agudizó la problemática social de las zonas productoras, por cuanto el café es uno de los pocos productos agrícolas de exportación que se sigue produciendo básicamente en pequeñas propiedades explotadas familiarmente, 94,7 \%. (Datos estimados basados en los datos de la página http://mailin.cafedecolombia.com/ productivo/infocafe.nsf).

11 El boleteo era una práctica que consistía en enviarle un papel o boleta a una persona para que abandone el pueblo, muchas veces, en la misma boleta se le ofrecía un irrisorio precio por la compra de sus propiedades. Fue una práctica que apareció en la llamada Violencia Política (entre liberales y conservadores) de los años cuarenta y cincuenta del siglo pasado, cuya inadecuada resolución condujo al encadenamiento con el conflicto armado actual. 


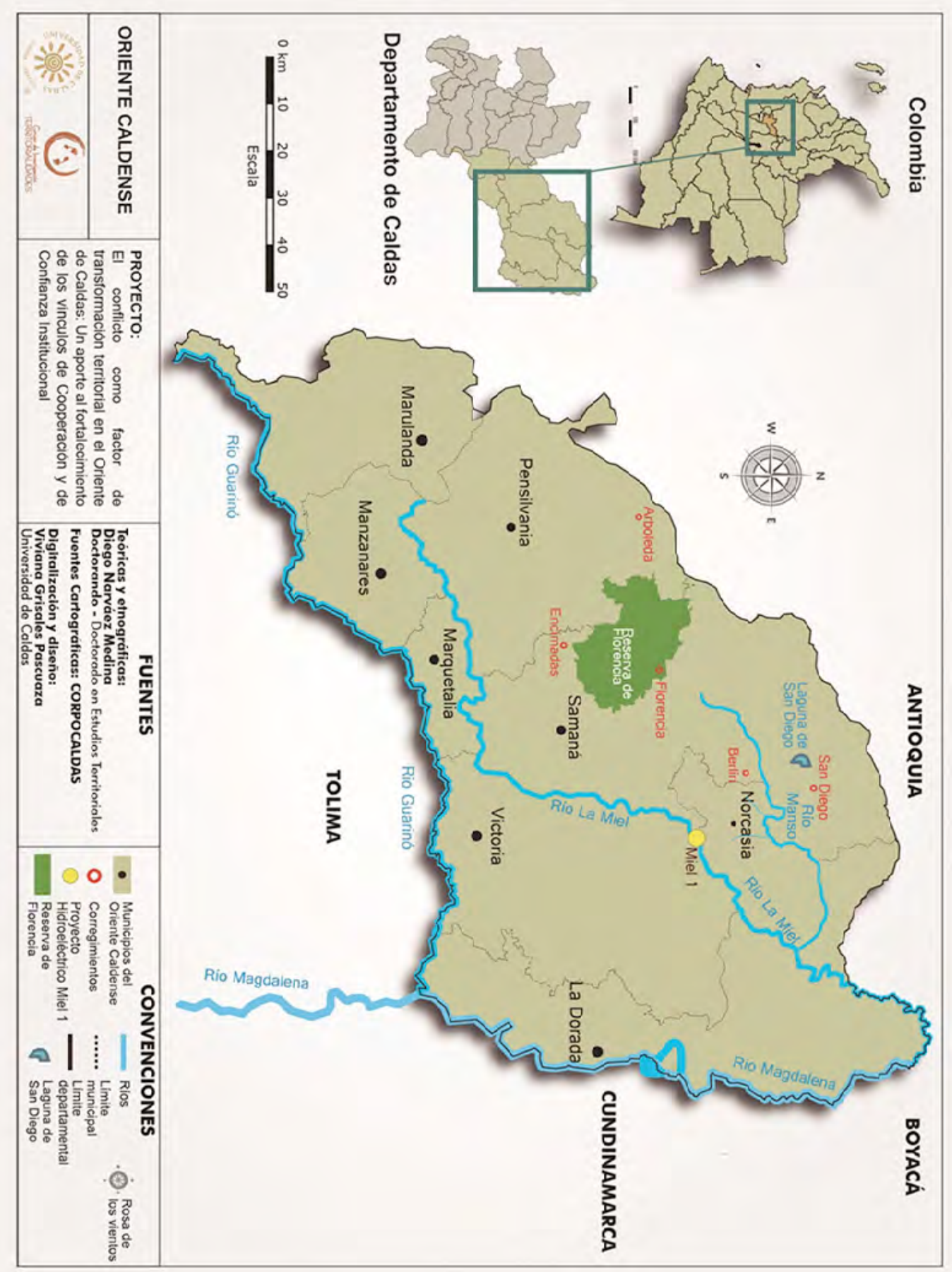

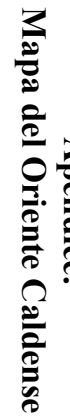

